\title{
TAGUCHI PARAMETRIC STUDY ON THE RADIAL AND TANGENTIAL CUTTING FORCES IN DRY HIGH SPEED MACHINING (DHSM)
}

\author{
H. Safari, M. Hatami * \\ Esfarayen University of Technology, Department of Mechanical Engineering, \\ Esfarayen, North Khorasan, Iran
}

Received 07.02.2020

Accepted 04.07.2020

\begin{abstract}
In this paper, $\mathrm{L}_{8}$ Taguchi array is applied to find the most important parameter effects on the radial and tangential cutting forces of a Ti-6Al-4V ELI titanium alloy in dry high speed machining (DHSM). The experiments are performed in four cutting speeds of 150, 200, 250, and $300 \mathrm{~m} / \mathrm{min}$ and two feed rates of 0.03 and $0.06 \mathrm{~mm} / \mathrm{rev}$. Also, two cutting tools in types of XOMX090308TR-ME06 of uncoated (H25) and TiAlN+TiN coated $(\mathrm{F} 40 \mathrm{M})$ are used. Results confirm that to minimize the resultant cutting force and radial cutting force, using the lower feed rate $(0.03 \mathrm{~mm} / \mathrm{rev})$ and higher cutting speed $(300 \mathrm{~m} / \mathrm{min})$ were considered as the best levels of studied factors.
\end{abstract}

Keywords: cutting force; titanium alloy; high speed machining; Taguchi method.

${ }^{*}$ Corresponding author: M. Hatami, m.hatami2010@gmail.com 


\section{Introduction}

Titanium alloys are a common type of difficult-to-machine materials that are used in many industrial fields such as aerospace, automotive, oil, and gas as well as medical devices. High strength-to-weight ratios, steadily high mechanical properties at high temperatures and high resistance to corrosion are some properties that make them preferred materials. Their properties of high thermal capacity and low thermal conductivity lead to a high increase in heat generated locally at the tool-chip interface, combined with the tendency of stickiness to cutting tools during machining [1]. It is known that approximately $60 \%$ of the total generated heat is kept inside the chips. Therefore, the bulk of the heat is evacuated out with the chips during high speed machining (HSM) [2]. Safari et al. [1], in an experimental study, investigated the cutting forces induced during high-speed end milling of titanium alloy (Ti-6Al-4V ELI) as well as the surface quality of the milled surfaces. Their experiment was performed in three cutting speeds of 200, 250, and $300 \mathrm{~mm} / \mathrm{min}$ and two feed rates of 0.03 and 0.06 $\mathrm{mm} /$ tooth and found that cutting force is inversely proportional to cutting speed regardless of cutting tool type. Also, they showed an increase in cutting speed at the lower feed rate improved surface roughness when a coated tool was used while no improvement in surface finish was detected when using an uncoated tool.

Devillez et al. [3] presented the results in terms of surface integrity and cutting forces when turning Inconel 718, in wet and dry conditions. They found that tensile stress is limited by the use of a lubricant. However, this effect of lubrication was reduced when increasing the cutting speed, leading to equivalent tensile stress values for a cutting speed of $80 \mathrm{~m} / \mathrm{min}$. Also, as showed in dry conditions, when cutting speed was increased, the peak tensile stress was reduced. At high cutting speed, the heat generated during chip formation is mostly evacuated by the chip. Li et al. [4] analyzed the tool wear propagation and cutting force variations in the end milling of the same material (Inconel 718) with coated carbide inserts.

Influence of different coolant strategies such as dry, wet, minimum quantity lubrication (MQL) and MQL with cooling air on performance in milling of the Ti-6Al4V alloy with uncoated cemented carbide inserts are investigated by Yuan et al. [5] which outcomes reveal that MQL with cooling air conditions provide lower cutting force, tool wear and surface roughness than those of tests under dry, wet and MQL conditions. In a complete review study, Yildiz and Nalbant [6] discussed on the cryogenic cooling in machining processes. In another study, machinability of titanium, Ti-6Al-4V, Ti-6Al-7Nb, and free-cutting brass was evaluated using a milling machine under four cutting conditions [7]. Cai et al. [8] for the same titanium alloy, Ti-6Al-4V, focused on the oil supply rate of minimum quantity lubrication and aimed to identify the effects of the minimum quantity lubrication applications with different oil supply rates in high-speed end milling. Shi et al. [9] used another titanium alloy, TC21, for studying its high speed machinability and showed that cutting force, cutting temperature, and tool life are greatly influenced by milling parameters, tool material, and tool wear. Investigation of high speed machining on hardened steel P20 at $50 \mathrm{HRC}$ by TiN coated and TiAlN coated solid carbide on the cutting forces, and tool wear are presented by $\mathrm{Wu}$ et al. [10].

Liu et al. [11] and Oosthuizen et al. [12] in different studies, investigated the effect of high speed milling by use of polycrystalline diamond (PCD) tools for Ti-6.5Al2Zr-1Mo-1V (TA15) and Ti6Al4V alloys, respectively and confirmed that PCD tool 
yielded longer tool life than a coated carbide tool at higher cutting speeds. A comparative experimental study of high speed machining of two major aerospace materials (titanium alloy $\mathrm{Ti}-6 \mathrm{Al}-4 \mathrm{~V}$ and Inconel 718) was performed by Fang and $\mathrm{Wu}$ [13] which they found that for both materials: as the feed rate increases, the cutting force, the thrust force, the resulting force, as well as the force ratio all increase. Some other studies on the milling process of Ti6Al4V can be found in the literature [14-15]. Optimization techniques are used widely by researchers in recent years in different engineering applications [16-21]. Zhang et al. [22] investigated the wear and cutting forces in the high speed end milling of Ti-6Al-4V alloy. Also, more studies on the machining and wear cutting forces on different alloys are performed by Aoyama et al. [23], Oxley [24] and Li et al. [25], which current results will be compared to them. Hanief and Charoo [26] used the artificial intelligence technique for optimizing the flank wear and surface roughness for Monel-400 as well as the Zhu and Zhang [27] modeling for high speed milling. Among the optimized techniques, Taguchi is more advantageous for the parametric study in machining tools. In that study, Taguchi determines that $\mathrm{L}_{8}[28-30]$ is a satisfactory array to find the optimum parameter level in this engineering application as well as previously used studies [28-30].

Based on the above literature review, a parametric study to find the optimum values for the tangential and radial cutting forces is necessary for the machining research works. The present study aims to apply the multi-objective Taguchi method to find the most critical parameter effects (cutting speeds, feed rates, and cutting tools) on the tangential and radial cutting force of Ti-6Al-4V ELI titanium alloy in dry high speed machining conditions.

\section{Experimental Procedure}

The used Ti-6Al-4V ELI titanium alloy was considered as a block of 100 $\mathrm{mm} \times 100 \mathrm{~mm} \times 450 \mathrm{~mm}$ in forged and annealed conditions. Chemical structure of the used titanium alloy and some of its mechanical properties are presented in Table 1 as informed by the manufacturer. Three-axis vertical machining center (DECKEL MAHO DMC $835 \mathrm{~V}$ ) capable of performing high-speed end milling was applied for this study. Four-component rotary dynamometer (Kistler, 9123C, maximum operation speed of $10,000 \mathrm{rev}=\mathrm{min}$ ) was used for determining cutting forces in radial and tangential directions during the machining process. Fig. 1 shows the high-speed end milling setup.

SECO Rhombus shape cemented carbide insert with designation XOMX090308TR-ME06 of uncoated (H25) and TiAlN+TiN coated (F40M) types are used as the cutting tools. Both types of cutting tool inserts have considered in the same dimension and geometry of $9.9 \mathrm{~mm}$ cutting edge length, $6.35 \mathrm{~mm}$ width, $3.65 \mathrm{~mm}$ thickness, $0.8 \mathrm{~mm}$ corner radius, $24^{\circ}$ rake angle, and $90^{\circ}$ major cutting edge angle. Cutting tool inserts were rigidly placed on the tool holder (R217.69-1612.3-09-1AN) with the shank and cutter diameters of 16 and $12 \mathrm{~mm}$, respectively. High-speed end milling was considered at constant depths of cut $(5.0 \mathrm{~mm}$ in axial and of $1.5 \mathrm{~mm}$ in radial directions), multiple cutting speeds $(150,200,250$, and $300 \mathrm{~m} / \mathrm{min})$ and two feed rates $(0.03$ and $0.06 \mathrm{~mm} / \mathrm{rev})$. 
Table1. Composition of Ti-6Al-4V ELI used and its mechanical properties.

\begin{tabular}{|c|c|c|c|c|c|c|c|c|c|c|}
\hline \multicolumn{8}{|c|}{ Content (wt.\%) } & \multicolumn{3}{|c|}{ Mechanical Properties } \\
\hline $\mathrm{Al}$ & $\mathrm{V}$ & $\mathrm{Fe}$ & $\mathrm{O}$ & $\mathrm{N}$ & $\mathrm{C}$ & $\mathrm{H}$ & $\mathrm{Ti}$ & $\begin{array}{c}\text { Yield } \\
\text { strength } \\
(\mathrm{MPa})\end{array}$ & $\begin{array}{c}\text { Tensile } \\
\text { strength } \\
(\mathrm{MPa})\end{array}$ & $\begin{array}{c}\text { Elongation } \\
(\%)\end{array}$ \\
\hline 5.85 & 4.1 & 0.10 & 0.08 & 0.0 & 0.0 & 0.001 & Bal. & 815 & 905 & 10 \\
\hline
\end{tabular}

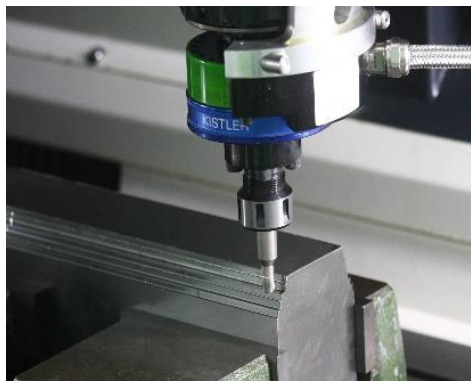

(a)

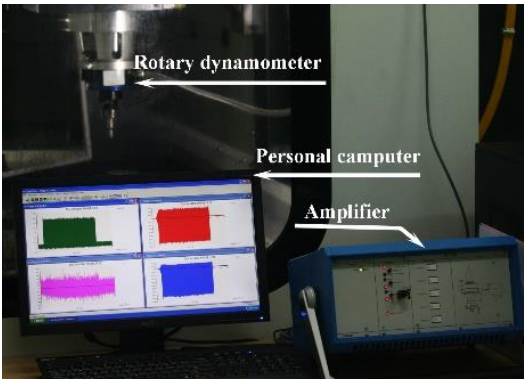

(b)

Fig. 1. a) milling setup and b) cutting force measurement instruments

\section{Taguchi method}

Taguchi is a method based on "ORTHOGONAL ARRAY" experiments, which offers much a reduced "variance" for the trials with "optimum settings "of control parameters. "Orthogonal Arrays" (OA) offer a set of minimum experiments, and Taguchi's Signal-to-Noise ratios $(\mathrm{S} / \mathrm{N})$, which are log functions of requested output, serve as objective functions for optimization, help in data analysis and prediction of optimum results. Taguchi realized that the best opportunity to reduce variation is during the design of a product and its manufacturing process [16-21, 28-30]. Based on this technique, the design of an experiment involves seven main steps as follows

1. Independent variables Selection

2. Considering the of number of levels for each independent variable

3. Orthogonal array selection

4. Assigning the independent variables to each column

5. Doing the experiments

6. Data analyzing

7. Inference

Based on the Taguchi method, three types of quality characteristics namely "higher is the better"; "nominal is the best" and "lower is the better" are available for the target design. As mentioned above, $\mathrm{S} / \mathrm{N}$ ratio is used to obtain the effects of desired values on the quality characteristics. On the other hand, regardless of quality characteristics, the more $\mathrm{S} / \mathrm{N}$ ratio refers to superior quality characteristics. So, the optimal levels of under study parameters will be determined based on the greatest $\mathrm{S} / \mathrm{N}$ ratio. $\mathrm{S} / \mathrm{N}$ ratio for described quality characteristics are:

a. higher is the better 


$$
S / N=-10 \log \left(\frac{1}{n} \sum_{i=1}^{n} \frac{1}{Y_{i}^{2}}\right)
$$

b. nominal is the best

$$
S / N=10 \log \left(\frac{\bar{Y}^{2}}{s^{2}}-\frac{1}{n}\right)
$$

c. lower is the better

$$
S / N=-10 \log \left(\frac{1}{n} \sum_{i=1}^{n} Y_{i}^{2}\right)
$$

where $S / N$ is the signal-to-noise ratio, $Y_{i}$ is the experimental results or responses of the study, $n$ is the number of repetitions under the same experimental conditions [28]. Hatami et al. [16] used Taguchi method for the optimization of a shell and helical tube heat exchanger experimentally and numerically. Qasim et al. [17] applied Taguchi for the parameter study of machining of AISI-1045 steel using ANOVA analysis. In this paper, tangential and radial cutting forces were normalized and non-dimensional using related percentage deviation or RPD to change the characteristics of both objective function to "lower is better" [16],

$$
R P D=\frac{\mid \text { method sol. }- \text { Best sol. } \mid}{\text { Best sol. }} \times 100
$$

After that, by considering a weighted mean function for both responses, a single objective will appear. Other optimizations and parametric studies were studied by other authors and can be found in [18-21].

Table 2. Factors and their Levels under study

\begin{tabular}{lccc}
\hline Levels\Factors & Cutting speed (Vc) (m/min) & Feed (mm/rev) & Cutting device \\
\hline Level 1 & 150 & 0.03 & F40M \\
Level 2 & 200 & 0.06 & H25 \\
Level 3 & 250 & - & - \\
Level 4 & 300 & - & - \\
\hline
\end{tabular}

\section{Results and discussions}

In this section, $\mathrm{L}_{8}$ orthogonal array of Taguchi will be used as Table 3 to find the optimum values for the cutting speed, feed rate, and cutting tools to have desired tangential and radial cutting forces. As shown in Fig. 2, in the down milling process, the cutter rotation and the feed of the work-piece are in the unit direction, the chip starts from the maximum thickness and ends to zero over a revolution [22]. So, the cutting forces perform on the tool along with the entry and exit of the cutting edge changes from the maximum to zero. During the machining process, the tool is under the instantaneous radial cutting force $\left(\mathrm{F}_{\mathrm{r}}\right)$ axial cutting force $\left(\mathrm{F}_{\mathrm{a}}\right)$ and tangential cutting 
force $\left(\mathrm{F}_{\mathrm{t}}\right)$. It is evident that large radial cutting forces make deflection in the tool as well as other uncertainty of the cutting system. This treatment affects the cutting efficiency, tool performance, and product quality. $\mathrm{F}_{\mathrm{a}}$ in milling operation can be negligible [23]. Actually, in the milling process, $F_{t}$ is the essential force that causes the material to be cut in the milling process and must be large enough. Therefore, machinist researchers need to approximate the cutting forces so they can control the machining process for better analyses on the tool's performance.

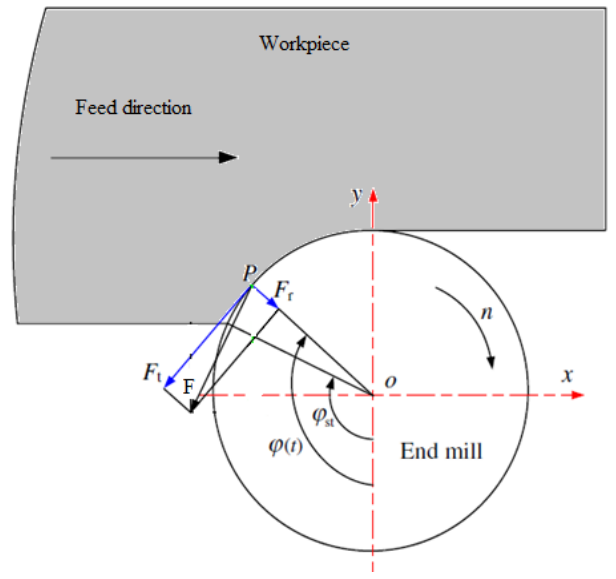

Fig. 2. Schematic drawing of the down end-milling process

In this study, two orthogonal components of force were measured, while the resultant cutting forces were calculated at different cutting conditions. Fig. $3(\mathrm{a}-\mathrm{d})$ illustrates the variation of cutting force components in two directions, $F_{t}, F_{r}$, and their resultant $(\mathrm{F})$ as a function of cutting speed $\left(\mathrm{V}_{\mathrm{c}}\right)$ for high speed dry end milling (HSDEM). The graphs in Fig. 2 confirm that $F_{t}$ and $F_{r}$ are the dominant cutting forces, which can be considered as the major indicator in monitoring the cutting process during the milling process. The result showed that $F_{t}, F_{r}$, and $F$ display a decreasing trend for both coated and uncoated carbide tools when the cutting speed increases at various feed rates. The generated cutting forces at higher cutting speeds are smaller in magnitude than those produced at lower cutting speeds. At high cutting speed, the greater temperature at the flow region reduces the contact area and chip thickness and hence reduces the cutting force magnitudes. This helps in removing the material at lower cutting forces. However, while increasing the cutting speed slightly, it reduces the cutting force. This result reveals a relationship between cutting speed and cutting force, which is in agreement with the theory proposed by Oxley [24]. 
a

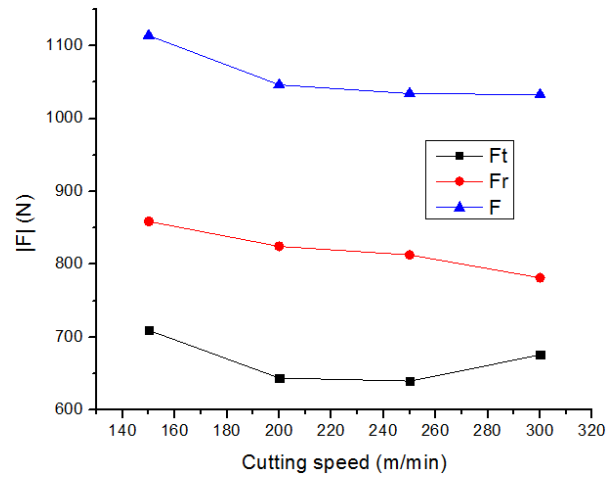

c

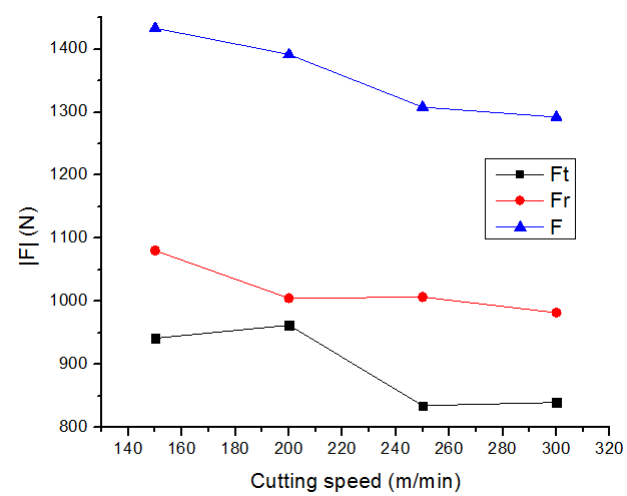

b

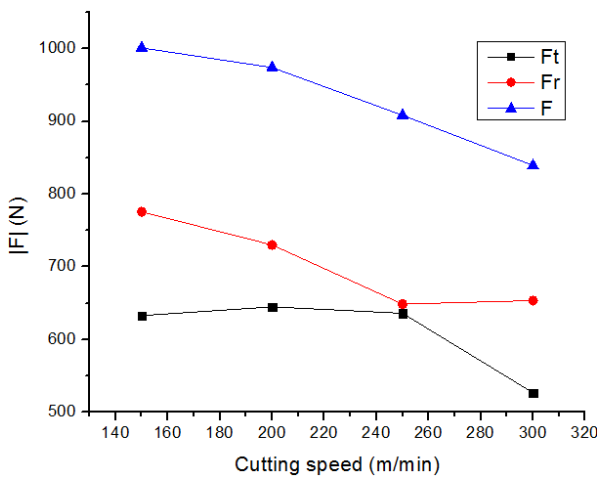

d

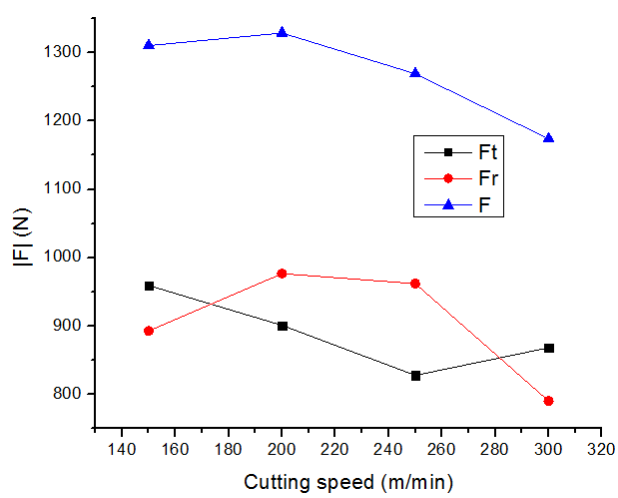

Fig. 3. Cutting forces versus cutting speed in HSDEM of Ti-6Al-4V ELI alloy, (a) $f=0.03 \mathrm{~mm} / \mathrm{tooth}$ and $F 40 M$ coated tool; $(b) f=0.03 \mathrm{~mm} /$ tooth and H25 uncoated; (c) $f=0.06 \mathrm{~mm} /$ tooth and F40M coated tool; and (d) $f=0.06 \mathrm{~mm} /$ tooth and H25 uncoated

Fig. 4 shows the effect of the feed rate on cutting forces in HSDEM of Ti-6A1$4 \mathrm{~V} \mathrm{ELI}$, at cutting speed of $150 \mathrm{~m} / \mathrm{min}$. As seen, the cutting force improved significantly as the feed rate increases when using both coated and uncoated carbide tools. This is in agreement with previous results reported by Li et al. [25]. This can be explained due to the thicker chip formation caused by higher feed rate, which induced higher pressure on the surface and resulted in an increased strain hardening process, and consequently, a significant rise in cutting forces will appear. 


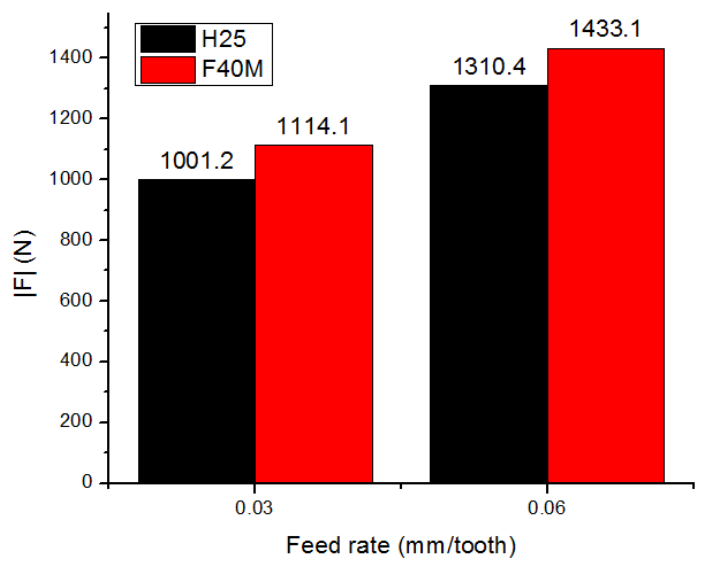

Fig. 4. Effect of the feed rate on the cutting forces in HSDEM of Ti-6Al-4V ELI at $V c=150 \mathrm{~m} / \mathrm{min}$.

A significant reduction in cutting forces obtained for using the uncoated insert in this experiment. Fig. 5 illustrates the effect of the cutting tool type on the cutting forces in HSDEM of Ti-6A1-4V ELI, at feed rate $0.06 \mathrm{~mm} /$ tooth. The graph shows a considerable decrease in cutting force when using uncoated insert under all cutting speeds. Considering the identical dimension and geometry for both applied tools, this outcome can be attributed to the sharp corner edge of the uncoated carbide tool. The coating layer enlarges the corner radius of the cutting tool, which causes a higher cutting force. Additionally, the surface roughness and the chemical reactivity of the coated material can affect the cutting forces. Shi et al. [9] have presented a similar finding when machining with sharp cutting tools. In this study, using an uncoated tool (H25) caused a reduction of cutting force between the ranges of 3 to $10 \%$ compared to the coated tool (F40M).

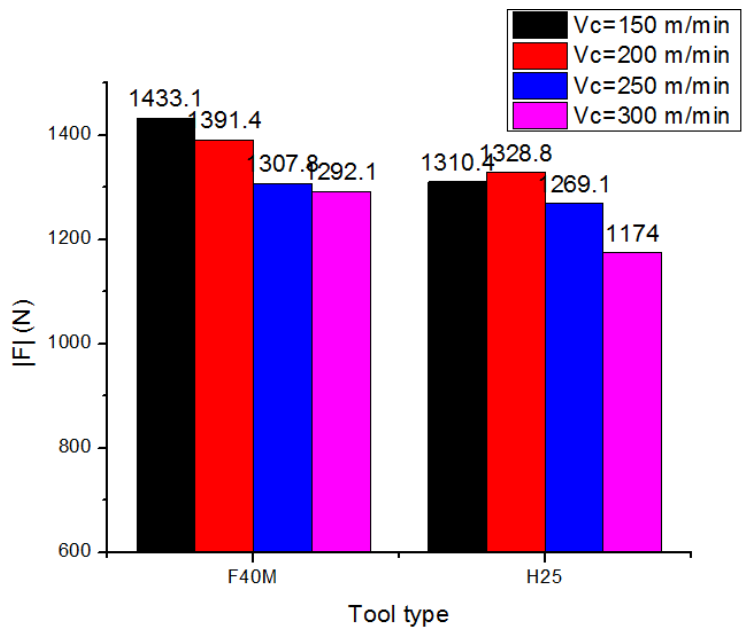

Fig. 5. Effect of the cutting tool type on the cutting forces in HSDEM of Ti-6A1-4V ELI at $f=0.06 \mathrm{~mm} /$ tooth. 
In the current study, a parametric study on the effective parameters on the cutting forces is performed by the Taguchi method. Table 2 shows these parameters and their levels in which their levels are selected based on the previous studies [1-2] and applicable experimental viewpoints. $\mathrm{L}_{8}$ orthogonal array of Taguchi will be used as presented in Table 3 to obtain the responses. All these cases were tested for dry conditions in order to obtain the results. Fig. 6 and 7 demonstrate the S/N ratio and means of means for these responses when "tangential force" and "radial force" considered as a single objective, respectively. The main advantage of multi-objective optimization is considering two or more responses to be optimized simultaneously, which in this study, these two objectives converted to a single objective and proceed by the solution. As seen, for tangential force, V1, F2, and C2 are appropriate levels of factors, while for radial force V4, F1 and C2 were considered as the best levels of factors to reach to considered goal due to higher $\mathrm{S} / \mathrm{N}$ ratio and lower deviation (mean of means). For reaching to a unit decision, a multi objective Taguchi is applied using RPD and resultant force (F). Fig. 8 shows these results, which confirms that V3\&V4 and F1 and $\mathrm{C} 2$ levels are the most appropriate parameters to have the minimum cutting force. Tangential cutting force is the force that causes to cut the material in the milling process. Therefore, it is very essential to increase the amount of this cutting force in order to increase material removal from the workpieces. Many researchers investigated the effect of high cutting speed on the cutting forces. Their results showed that the cutting force generated at lower cutting speeds are higher in magnitude than those generated at the higher cutting speed. So, in order to obtain the higher tangential cutting force, employing the lower cutting speed is recommended. On the other hand, large radial cutting forces cause tool deflection and other instability of the cutting system. So, it is better to decrease this force, which is possible when using higher cutting speeds. Utilizing the higher cutting speeds causes the rise of cutting temperature and developed friction, which affected more heat generation during dry machining. Therefore, the enhanced plastic flow of material and thermal softening phenomena, leading to lower cutting force, are required. This implies that during dry machining, thermal softening is reduced, the cutting force through the lowering of the shear strain.

Using the higher feed rate makes the thicker chip formation, which produced higher pressure on the surface, and resulted in an increased work hardening process, and consequently, a significant rise in cutting forces will occur. This is in agreement with the results recommended by the Taguchi method. The outcome of the Taguchi method recommended using the uncoated $\mathrm{H} 25$ tool type, which can be attributed to the sharp corner edge of the uncoated carbide tool. The coating layer increases the corner and edge radius of the cutting tool, which adversely influences the cutting force. Furthermore, the surface roughness and the chemical reactivity of the coated material can affect the cutting forces. That is why the performance of the uncoated tool was much better than the coated tool. 

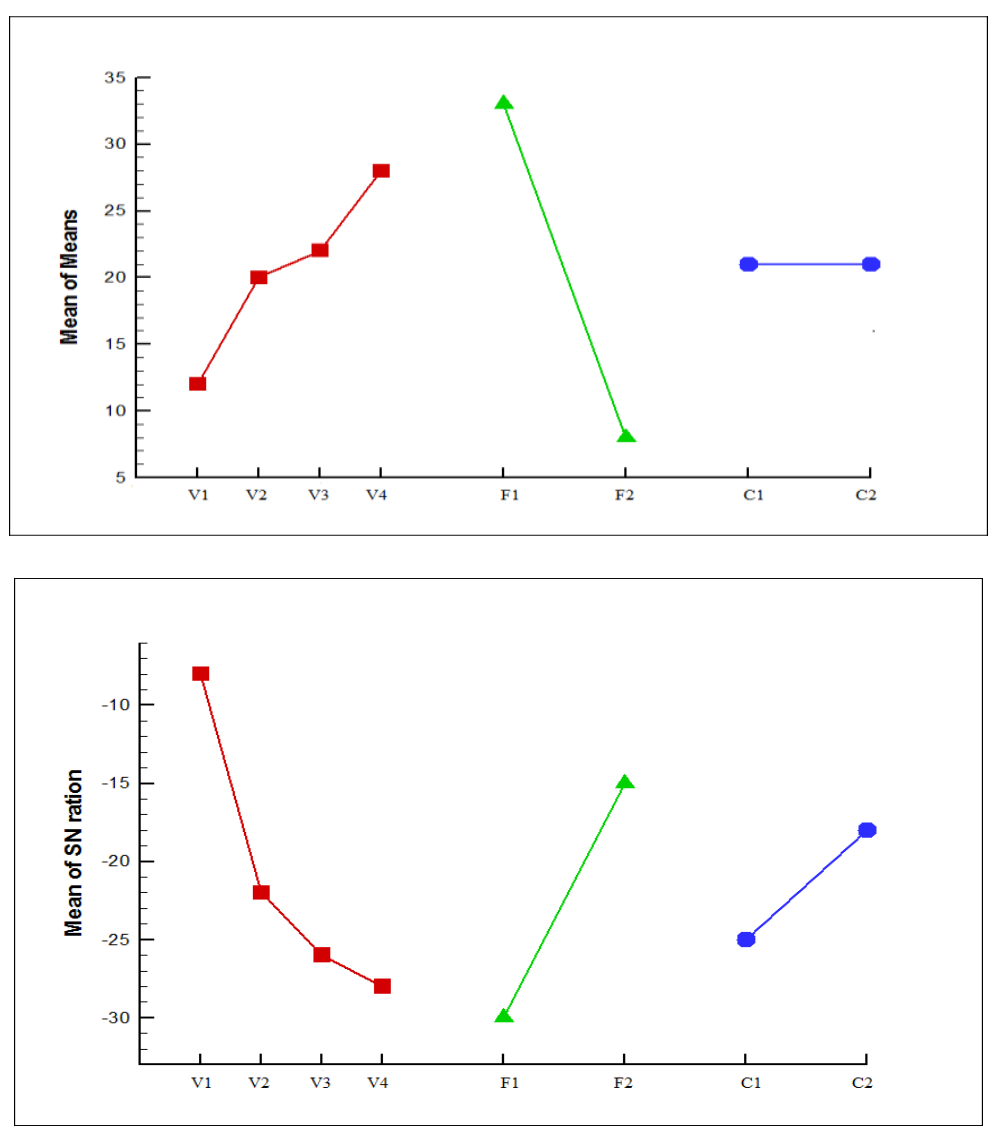

Fig. 6. Mean of Means and Mean of S/N ratio for Ft response 

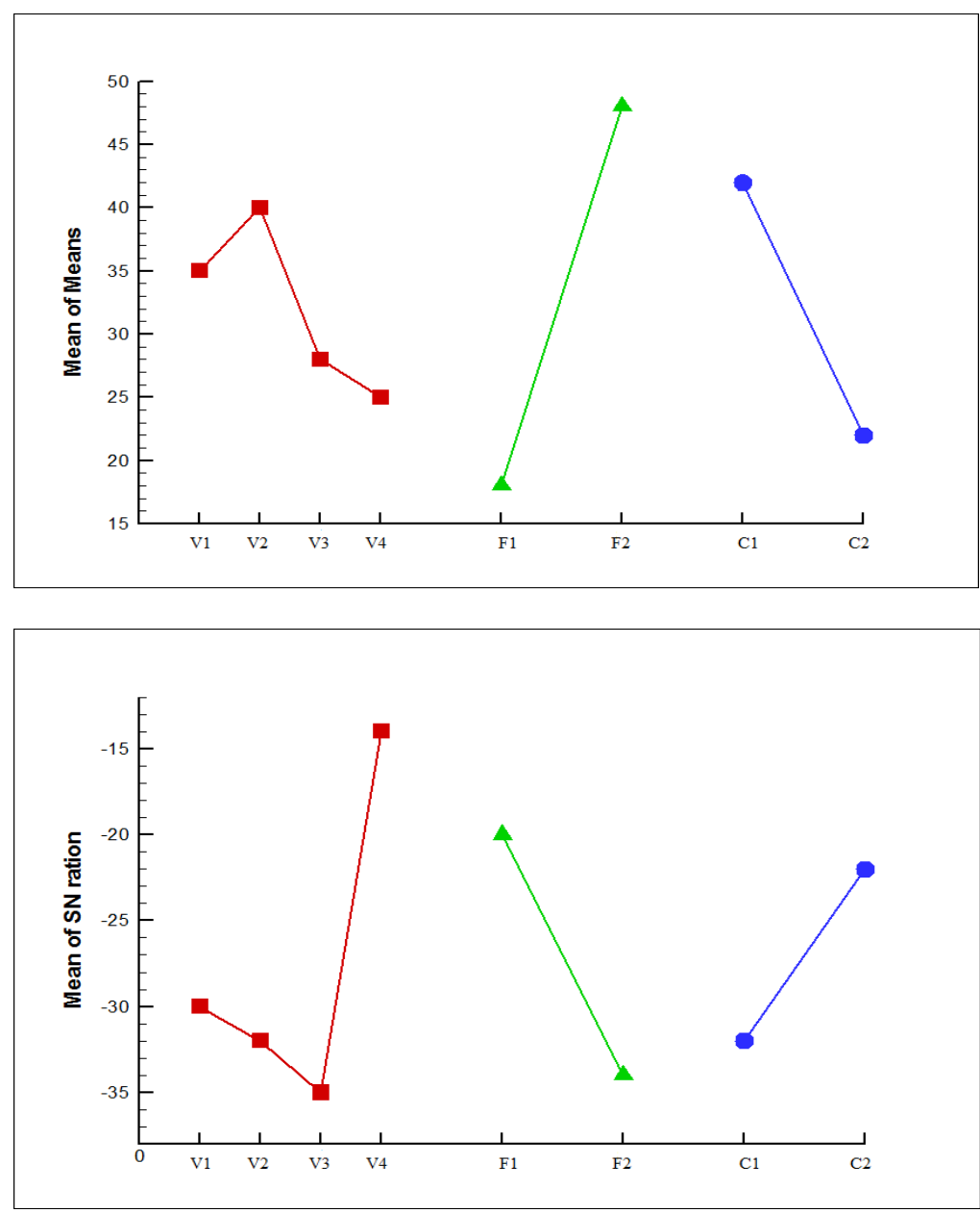

Fig. 7. Mean of Means and Mean of S/N ratio for Fr response 

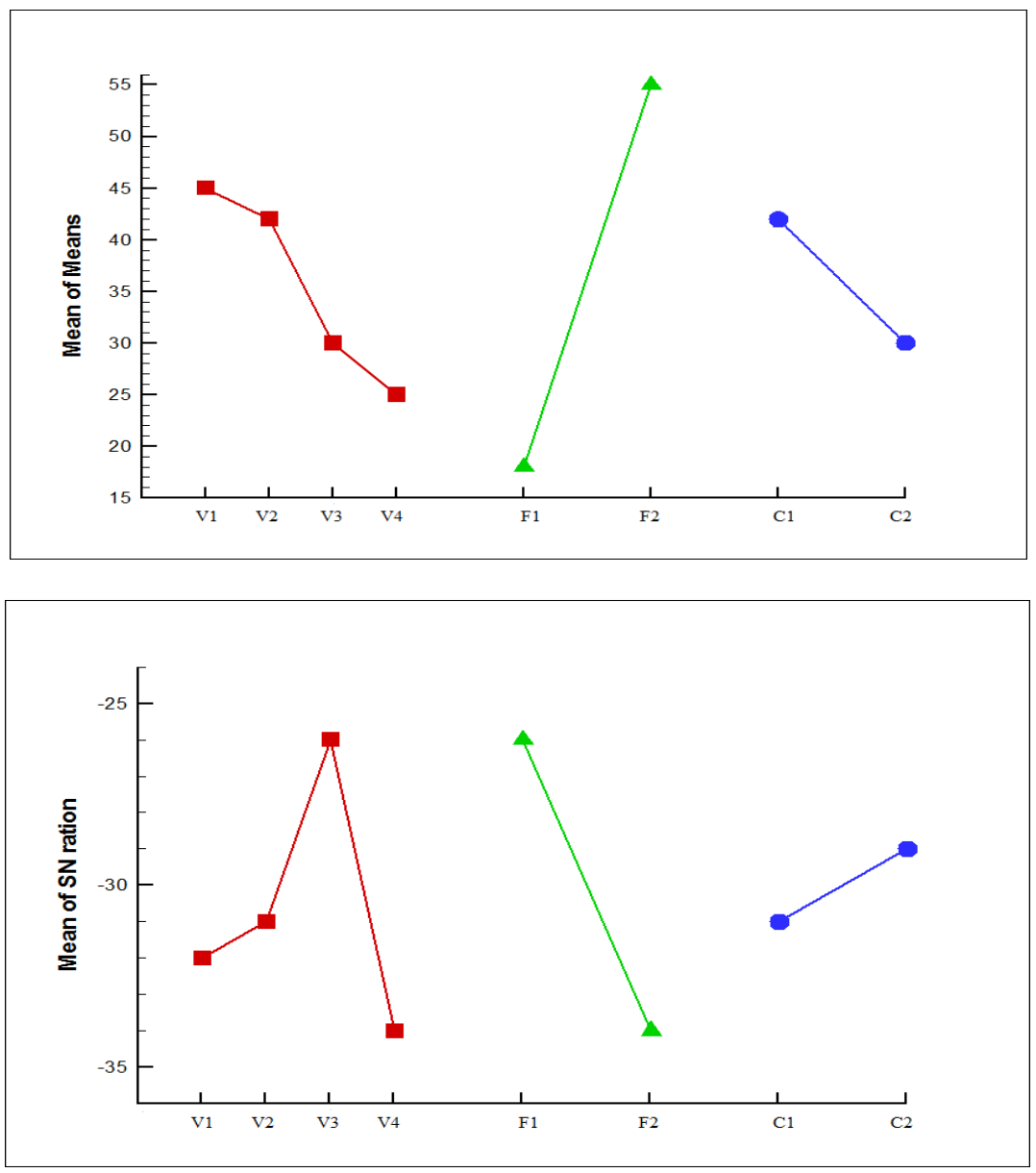

Fig. 8 Mean of Means and Mean of S/N ratio for F response.

Table 3. $L_{8}$ orthogonal arrays for applied Taguchi.

\begin{tabular}{lccc}
\hline $\begin{array}{l}\text { Test } \\
\text { number }\end{array}$ & $\begin{array}{c}\text { Level of } \\
V c\end{array}$ & $\begin{array}{c}\text { Level of } \\
f(\mathrm{~mm} / \mathrm{rev})\end{array}$ & $\begin{array}{c}\text { Level of } \\
\text { cutting tools }\end{array}$ \\
\hline 1 & 1 & 1 & 1 \\
2 & 1 & 2 & 2 \\
3 & 2 & 1 & 1 \\
4 & 2 & 2 & 2 \\
5 & 3 & 1 & 2 \\
6 & 3 & 2 & 1 \\
7 & 4 & 1 & 2 \\
8 & 4 & 2 & 1 \\
\hline
\end{tabular}




\section{Conclusions}

Based on the $\mathrm{L}_{8}$ Taguchi parametric investigation conducted on the radial and tangential cutting forces in a DHSM process, the following conclusions can be drawn:

1- From the total results obtained in this study, a sharper cutting edge of the uncoated tool facilitates lower cutting force when compared to that of the coated tool.

2- To maximize tangential cutting force, employing lower cutting speed $(150 \mathrm{~m} / \mathrm{min})$ and higher feed rate $(0.06 \mathrm{~mm} / \mathrm{rev})$ were appropriate levels of factors. Cutting force is inversely proportional to cutting speed, and by increasing the feed rate, the cutting forces increase.

3- In order to minimize the resultant the cutting force and radial cutting force, utilizing the lower feed rate $(0.03 \mathrm{~mm} / \mathrm{rev})$ and higher cutting speed $(300 \mathrm{~m} / \mathrm{min}$ ) were considered as the best levels of factors to reach this goal.

\section{References}

[1] H. Safari, S. Sharif, S. Izman, H. Jafari, D. Kurniawan: Mater Manuf Processes, 29 (2014) 350-356.

[2] H. Safari, S. Sharif, S. Izman, H. Jafari: Int J Adv Manuf Technol, 78 (2015) 651-657.

[3] A. Devillez, G. Le Coz, S. Dominiak, D. Dudzinski: J Mater Process Technol, 211 (2011) 1590-1598.

[4] H.Z. Li, H. Zeng, X.Q. Chen: J Mater Process Technol, 180 (2006) 296-304.

[5] S.M. Yuan, L.T. Yan, W.D. Liu, Q. Liu: J Mater Process Technol, 211 (2011) 356-362.

[6] Y. Yildiz, M. Nalbant: Int J Mach Tools Manuf, 48 (2008) 947-964.

[7] M. Kikuchi, O. Okuno: Dent Mater J, 23 (2004) 37-45.

[8] X. Jiang Cai, Z. Qiang Liu, M. Chen, Q. Long An: Proc IMechE Part B:J Eng Manuf, 226 (2012) 1784-1792.

[9] Q. Shi, L. Li, N. He, W. Zhao, X. Liu: Int J Adv Manuf Technol, 64 (1-4) (2013) 49-54.

[10] L.D. Wu, C.Y. Wang, D.H. Yu, Y.X. Song: Adv Mater Res, 69-70 (2009) 418422.

[11] P. Liu, J. Xu, Y. Fu: J Zhejiang Univ Sci A (Appl Phys \& Eng), 12 (1) (2011) 56-62.

[12] G.A. Oosthuizen, G. Akdogan, N. Treurnicht: Int J Adv Manuf Technol, 52 (2011) 929-935.

[13] N. Fang, Q. Wu: J Mater Process Technol, 209 (2009) 4385-4389.

[14] M.J. Bermingham, J. Kirsch, S. Sun, S. Palanisamy, M.S. Dargusch: Int J Mach Tool Manuf, 51 (2011) 500-511.

[15] S. Zhang, J.F. Li, J. Sun, F. Jiang: Int J Adv Manuf Technol, 46 (2010) 69-78.

[16] M. Hatami, D.D. Ganji, M. Gorji-Bandpy: Energy Convers Manage, 97 (2015) 26-41.

[17] A. Qasim, S. Nisar, A. Shah, M.S. Khalid, M.A. Sheikh: Simul Model Pract Theory, 59 (2015) 36-51.

[18] M. Hatami, M. Jafaryar, D.D. Ganji, M. Gorji-Bandpy: Int Commun Heat Mass Trans, 57 (2014) 254-263.

[19] M. Rahimi-Gorji, O. Pourmehran, M. Hatami, D.D. Ganji: Euro Physic J Plus, 130 (2) (2015) 1-21. 
[20] M. Hatami, M.C.M. Cuijpers, M. D. Boot: Energy Convers Manage, 106 (2015) 1057-1070.

[21] M. Hatami, D. Song, D. Jing: Int J Heat Mass Transf, 98 (2016) 758-767.

[22] S. Zhang, J. Li, J. Sun, F. Jiang: Int J Adv Manuf Technol, 46 (1-4) (2010) 6978.

[23] T. Aoyama, Y. Kakinuma, M. Yamashita, M. Aoki: CIRP Annal Manuf Technol, 57 (1) (2008) 125-128.

[24] P. Oxley, Mechanics of Machining: an Analytical Approach to Assessing Machinability, Ellis Horwood Limited, United Kingdom, 1989.

[25] H. Li, H. Zeng, X. Chen: J Mater Process Technol, 180 (1) (2006) 296-304.

[26] M. Hanief, M.S. Charoo: Metall Mater Eng, 26 (2020) 57-69.

[27] K. Zhu, Y. Zhang: Mech Sys Signal Process, 115 (2019) 147-161.

[28] G. Al, U. Özdemir, Ö. Aksoy: Ecotoxicol environl saf, 98 (2013) 36-40.

[29] S.S. Raj, P.R. Reddy: Int J Eng Sci Technol, 3 (11) (2011).

[30] Gh. Asgari, A. Dayari, M. Ghasemi, A. Seid-Mohammadi, V.K. Gupta, Sh. Agarwal: J Mol Liq, 275 (2019) 251-264.

$$
\text { (c) (7) Creative Commons License }
$$

This work is licensed under a Creative Commons Attribution 4.0 International License. 